\title{
Isolation of a novel cyanophage infectious to the filamentous cyanobacterium Planktothrix agardhii (Cyanophyceae) from Lake Donghu, China
}

\author{
E-Bin Gao, Xiu-Ping Yuan, Ren-hui Li, Qi-Ya Zhang* \\ State Key Laboratory of Freshwater Ecology and Biotechnology, Institute of Hydrobiology, Chinese Academy of Sciences, \\ Graduate University of the Chinese Academy of Sciences, Wuhan 430072, PR China
}

\begin{abstract}
A previously unknown cyanophage, PaV-LD (Planktothrix agardhii Virus isolated from Lake Donghu), which causes lysis of the bloom-forming filamentous cyanobacterium $P$. agardhii, was isolated from Lake Donghu, Wuhan, China. PaV-LD only lysed P. agardhii strains isolated from Lake Donghu and not those isolated from other lakes. The PaV-LD particle has an icosahedral, non-tailed structure, ca. 70 to $85 \mathrm{~nm}$ (mean $\pm \mathrm{SD}=76 \pm 6 \mathrm{~nm}$ ) in diameter. PaV-LD was stable at freezing temperature, but lost its infectivity at temperatures $>50^{\circ} \mathrm{C}$. Lysis of host cells was delayed about $3 \mathrm{~d}$ after the PaV-LD treatment with chloroform, and the virus was inactivated by exposure to low $\mathrm{pH}(\leq 4)$. The latent period and burst size of the PaV-LD were estimated to be 48 to $72 \mathrm{~h}$ and about 340 infectious units per cell, respectively. The regrowth cultures of surviving host filaments were not lysed by the $\mathrm{PaV}$-LD suspension. To our knowledge, this is the first isolation and cultivation of a virus infectious to the filamentous bloom-forming cyanobacterium Planktothrix from a freshwater lake.
\end{abstract}

KEY WORDS: Cyanophage · Planktothrix agardhii - Viral infection - Blooms · Cyanobacteria • Freshwater lake

\section{INTRODUCTION}

The filamentous cyanobacterium Planktothrix agardhii is one of the typical harmful bloom-causing cyanobacteria and can be commonly detected in a large range of aquatic environments (Scheffer et al. 1997, Briand et al. 2002, Davis et al. 2003), including shallow eutrophic freshwater lakes and reservoirs used to provide drinking water. Some strains can produce hepatotoxic microcystins that are toxic to the health of animals including humans (Tonk et al. 2005, Wiegand \& Pflugmacher 2005). Consequently, the contamination of freshwater bodies by harmful cyanobacteria is now considered to be an increasing environmental hazard in the world (Chorus \& Bartram 1999, Li et al. 2008, www.sciencedaily.com/releases/2008/04/080403140928. htm). Water management usually places a great deal of emphasis on physical and chemical factors that drive the growth and production of harmful cyanobacteria.
Viruses are ubiquitous, dynamic and numerically dominant components of microbial communities in natural aquatic ecosystems (Bergh et al. 1989, Wommack \& Colwell 2000, Suttle 2005), and most of them are thought to be infectious to bacteria or cyanobacteria (Proctor \& Fuhrman 1990). Since the first isolation of the cyanophage LPP-1, infectious to the freshwater cyanobacterial genera Lyngbya, Plectonema and Phormidium (Safferman \& Morris 1963), viruses or viruslike particles have been detected in other genera of cyanobacteria, including Anacystis, Synechococcus, Prochlorococcus, Anabaena, Nostoc and Microcystis (Padan \& Shilo 1973, Phlips et al. 1990, Lu et al. 2001, Tucker \& Pollard 2005, Yoshida et al. 2006, Wang \& Chen 2008). These detections have greatly stimulated the interest in the ecological implications of viral infection for cyanobacterial dynamics in aquatic environments (Suttle \& Chan 1994, Suttle 2000). Some reports have suggested that cyanophages are significant bio- 
logical agents of cyanobacterial mortality, and play an important role in regulating primary productivity and host population dynamics (Suttle et al. 1990, Hewson et al. 2001, Yoshida et al. 2008).

Despite the significance of viruses in biological control of cyanobacteria blooms, detailed knowledge on the potential effects of viral infection on cyanobacteria is still lacking. This is because it is relatively difficult to select known cyanobacterial species as potential hosts for the isolation of an anonymous virus from natural aquatic environments (Weinbauer 2004). This has largely restricted the isolation and cultivation of cyanobacterial phage-host systems and relevant studies on the potential effects of viral infection on cyanobacterial populations and production. To better understand the important roles of cyanophages on the bloom dynamics and biological control of harmful algae, our laboratory initiated a program in 2004 to investigate the distribution, morphology and abundance of virioplankton in Lake Donghu (Liu et al. 2005,
2006) and isolate the lytic agents of harmful bloomforming cyanobacteria. In the present study, we focus on the isolation and characterization of a cyanophage that infects and lyses the harmful cyanobacterium Planktothrix agardhii from a freshwater lake and look for efficient strategies for the control of cyanobacterial blooms in freshwater environments. This cyanophage was tentatively named PaV-LD (Planktothrix agardhii Virus isolated from Lake Donghu) after its host and the location from which it was isolated.

\section{MATERIALS AND METHODS}

Cyanobacterial cultures and growth conditions. Ten cyanobacterial species (24 strains) used for isolation of cyanophages and for host range experiments are shown in Table 1. They were obtained from the Harmful Algae Collection and Algal Resources Collection, Institute of Hydrobiology, Academy of

Table 1. Cyanobacterial strains used in this study, their localities and dates of isolation and their susceptibility to cyanophage PaV-LD infection. FACHB strains used in this study were purchased from the Algal Resources Collection, Institute of Hydrobiology, Chinese Academy of Sciences. HAB strains were obtained from the Harmful Algae Collection, Institute of Hydrobiology, Chinese Academy of Sciences. (+): lysed cells; (-): cells not lysed

\begin{tabular}{|c|c|c|c|}
\hline \multirow[t]{2}{*}{ Species and strains } & \multicolumn{2}{|l|}{ Isolation } & \multirow[t]{2}{*}{ Susceptibility } \\
\hline & Locality & Date & \\
\hline \multicolumn{4}{|l|}{ Planktothrix agardhii } \\
\hline НАB0637 & Lake Donghu, Wuhan,China & Sep 2006 & + \\
\hline НАВ0638 & Lake Donghu, Wuhan,China & Sep 2006 & + \\
\hline HAB0642 & Lake Donghu, Wuhan, China & Sep 2006 & + \\
\hline HAB0643 & Lake Donghu, Wuhan, China & Sep 2006 & + \\
\hline HAB1128 & Fusha Down, Guangdong, China & Jun 2006 & - \\
\hline НАВ0403 & Fuchun River, Zhejiang, China & Sep 2006 & - \\
\hline НАВ0169 & Hedao, Zhejiang, China & Aug 2006 & - \\
\hline НАB2364 & Unknown, Beijing, China & Sep 2006 & - \\
\hline HAB0325 & Dianchi, Yunnan, China & Apr 2006 & - \\
\hline \multicolumn{4}{|l|}{ Planktothricoides raciborskii } \\
\hline НАВ0306 & Fishing Pond, Wuhan, China & May 2006 & - \\
\hline НАВ0309 & Fishing Pond, Wuhan, China & May 2006 & - \\
\hline Anabaena PCC7120 & France & Unknown & - \\
\hline Anabaena spirioides HAB0502 & Fishing Pond, Wuhan, China & Aug 2006 & - \\
\hline Anabaena flos-aquae HAB0337 & Fishing Pond, Wuhan, China & May 2006 & - \\
\hline \multicolumn{4}{|l|}{ Anabaena variabilis } \\
\hline FACHB112 & Lake Donghu, Wuhan,China & Unknown & - \\
\hline FACHB113 & Lake Donghu, Wuhan,China & Unknown & - \\
\hline \multicolumn{4}{|l|}{ Microcystis aeruginosa } \\
\hline FACHB569 & Lake Donghu, Wuhan,China & Unknown & - \\
\hline FACHB925 & Lake Donghu, Wuhan,China & Unknown & - \\
\hline FACHB524 & Lake Donghu, Wuhan, China & Unknown & - \\
\hline HAB0125 & Lake Taihu, Jiangsu, China & Aug 2006 & - \\
\hline Microcystis smithii HAB0138 & Fishing Pond, Wuhan, China & Sep 2006 & - \\
\hline Microcystis botrys HAB0329 & Fishing Pond, Wuhan, China & May 2006 & - \\
\hline \multicolumn{4}{|l|}{ Aphanizomenon issatschenkoi } \\
\hline HAB1313 & Lake Chidonghu, Wuhan,China & Aug 2006 & - \\
\hline НАB2389 & Lake Donghu, Wuhan,China & Sep 2006 & - \\
\hline
\end{tabular}


Sciences, China. Each cyanobacterial strain used in this experiment was clonally grown in medium BG-11 at $26^{\circ} \mathrm{C}$ under a $14 \mathrm{~h}$ light:10 h dark cycle of 30 to $40 \mu \mathrm{mol}$ photons $\mathrm{m}^{-2} \mathrm{~s}^{-1}$ with cool white fluorescent illumination.

Isolation of cyanophage. A sample of freshwater collected from Lake Donghu located in Wuhan, Hubei Province, China, in June 2007, was sent to the laboratory within $6 \mathrm{~h}$ after sampling. A total of $200 \mu \mathrm{l}$ of the natural freshwater sample were mixed with $5 \mathrm{ml}$ of BG-11 liquid medium, and then were incubated for $2 \mathrm{wk}$ at $26^{\circ} \mathrm{C}$ under the same lighting conditions as mentioned above. The incubated water sample was filtered through a $0.45 \mu \mathrm{m}$ pore-size Nucleopore membrane filter to remove zooplankton, phytoplankton, bacteria and cell debris. Aliquots of $0.2 \mathrm{ml}$ of the filtrate were added to $0.8 \mathrm{ml}$ of exponentially growing cultures of Planktothrix agardhii strains per well in 24well culture plates and were incubated under the conditions described above. Control cultures received the $0.45 \mu \mathrm{m}$ filtrate that had been heat-treated at $100^{\circ} \mathrm{C}$ for $15 \mathrm{~min}$. The cultures were visually inspected, and checked by optical microscopy every day to examine the changes of filamentous morphology.

The PaV-LD suspension from these positive samples was obtained by the 3 cycles extinction dilution procedure (Nagasaki \& Yamaguchi 1997). In brief, the supernatant of the lysed cultures was diluted with BG11 medium in a series of 10 -fold dilution steps. Aliquots of $0.2 \mathrm{ml}$ of each dilution were transferred into successive $1 \mathrm{ml}$ drops of fresh, exponentially growing Planktothrix agardhii cultures with 4 replicates in 24-well culture plates and incubated under the conditions described above. The culture lysate in the highest dilution of the first assay was centrifuged at $8000 \times g$ for $15 \mathrm{~min}$ at $4^{\circ} \mathrm{C}$ to remove cell debris, and the supernatant was carried over to the second extinction dilution assay. This process was repeated 3 times. The lysate in the highest dilution of the third assay was inoculated to a fresh, exponentially growing culture of $P$. agardhii. The resultant lysate was used as the PaVLD suspension in the present study. The number of infectious units of the PaV-LD suspension was estimated by using the most-probable number technique (Saitoh et al. 2003). Furthermore, to rule out potential lysis by bacteria the PaV-LD suspension was also tested for infectivity by filtration through $0.2 \mu \mathrm{m}$ poresize syringe filters.

Host range test. The host range specificity of the virus was determined by adding $0.2 \mathrm{ml}$ aliquots of the $\mathrm{PaV}$-LD suspension to triplicate $0.8 \mathrm{ml}$ cultures of the exponentially growing cyanobacterial species listed in Table 1. Growth of host cultures without the PaV-LD suspension was also monitored to serve as a control. The cultures were incubated under the same condi- tions of light and temperature as described for the growth of Planktothrix agardhii cultures. The occurrence of host cells lysis was daily monitored by optical microscopy. Strains that were not lysed after $14 \mathrm{~d}$ of incubation were considered to be not susceptible hosts for the virus.

Based on the results of these host tests, Planktothrix agardhii strain HAB0637, which was isolated from Lake Donghu in 2006 and identified on the basis of morphological description in existing literature (Suda et al. 2002), was used as the main host in the following experiments.

Growth experiment. Cultures, $100 \mathrm{ml}$ in volume, of exponentially growing Planktothrix agardhii HAB0637 were inoculated in duplicate with $10 \%(\mathrm{v} / \mathrm{v})$ of the PaV-LD suspension. Cultures without the PaV-LD suspension served as the controls. Growth of $P$. agardhii cultures was determined fluorometrically in vivo by measuring the chlorophyll content of host cells using a microplate reader (SpectraMax M2, Molecular Devices) on a daily basis. Fluorescence was determined with an excitation of $400 \mathrm{~nm}$ wavelength, emission of $800 \mathrm{~nm}$ and a cut-off filter of $695 \mathrm{~nm}$. During the experiments, aliquots of the infected and non-infected host cultures were prepared for transmission electron microscopy.

To estimate the latent period and burst size of $\mathrm{PaV}$ LD, a 1-step growth experiment was designed according to the method described by Yoshida et al. (2006). The new phage suspension was appropriately diluted with liquid BG-11 medium and inoculated into $100 \mathrm{ml}$ of exponentially growing Planktothrix agardhii HAB0637 culture. The initial density of host cells was about $10^{5}$ cells $\mathrm{ml}^{-1}$, the titer of the PaV-LD was about $10^{5}$ infectious units $\mathrm{ml}^{-1}$ and the multiplicity of infection was about 0.45 . After inoculation, the density of host cells was periodically determined by direct counting under a microscopic, and the titer of the PaV-LD was estimated by the most-probable number technique (Saitoh et al. 2003). The incubation conditions were as described above.

Viral infectivity of survived filaments. To characterize Planktothrix agardhii cells that survived in the lysed culture after viral infection, the surviving filaments were collected and inoculated into fresh BG-11 medium. The sensitivity of regrowth cultures of $P$. agardhii to viral infectivity was tested by adding $20 \%$ (v/v) aliquots of fresh viral suspension to exponentially growing cultures. Cultures were monitored for evidence of lysis by optical microscopic observation.

Transmission electron microscopy. The infected or non-infected Planktothrix agardhii cultures were both withdrawn $48 \mathrm{~h}$ after inoculation and fixed with $2.5 \%$ glutaraldehyde. Fixed cells were harvested by centrifugation at $800 \times g$ for $5 \mathrm{~min}$ at $4^{\circ} \mathrm{C}$. The cell pellets 
were post-fixed with $2 \%$ osmium tetroxide in sodium cacodylate buffer for 1 to $2 \mathrm{~h}$, dehydrated in a graded acetone series, and embedded in LR White acrylic resin. Ultra-thin sections were post-stained with $2 \%$ uranyl acetate and $3 \%$ lead citrate and observed at $100 \mathrm{kV}$ with a JEOL 1230 transmission electron microscope.

The PaV-LD suspension was absorbed onto carboncoated copper grids by centrifuging at $100000 \times g$ for $1.5 \mathrm{~h}$ in a Beckman Optima L-90 K ultracentrifuge in a SW 41 swing-out rotor (Beckman). Grids were stained with a drop of $2 \%$ uranyl acetate for $10 \mathrm{~min}$. The excess dye was removed with filter paper. After the grid was dried at room temperature, stained PaV-LD particles were observed at $80 \mathrm{kV}$ with the transmission electron microscope. The diameter of cyanophages was estimated from the stained images.

Detection of physico-chemical characteristics. Heat stability of the PaV-LD was tested with treatments in water baths from 30 to $100^{\circ} \mathrm{C}$ in steps of $5^{\circ} \mathrm{C}$ for $15 \mathrm{~min}$ each. The treated samples were cooled on ice for $5 \mathrm{~min}$ and inoculated in duplicate into exponentially growing cultures of Planktothrix agardhii. A culture of $P$. agardhii infected with a non-treated virus lysate was used as a positive control and a noninfected culture of $P$. agardhii served as a negative control. To test the stability of the virus at low temperatures, aliquots of the PaV-LD suspension were stored at $-20,-80$ and $-196^{\circ} \mathrm{C}$ (liquid nitrogen) in the dark with cryoprotectants. After $1 \mathrm{wk}$, the frozen samples were thawed at room temperature and added to exponentially growing cultures of $P$. agardhii. A non-frozen sample was used as positive control. The stability of the PaV-LD suspension to acidic or alkalic conditions was tested by exposure to $\mathrm{pH}$ levels ranging from $\mathrm{pH} 3$ to $\mathrm{pH} 10$ in $1 \mathrm{pH}$ unit increments. After $1 \mathrm{~h}$ incubation at room temperature, the various $\mathrm{pH}$ treatments were adjusted to $\mathrm{pH} 8.0$ with $0.1 \mathrm{~N} \mathrm{HCl}$ or $0.1 \mathrm{~N} \mathrm{NaOH}$ and were inoculated into fresh cultures of $P$. agardhii. Aliquots of media that were treated in the same way were used as controls. For determination of the stability of chloroform, $1 \mathrm{ml}$ of the PaV-LD suspension was vigorously shaken with an equal volume of chloroform for $5 \mathrm{~min}$. Chloroform was separated by centrifugation at $5300 \times g$ for $5 \mathrm{~min}$, and the aqueous phase containing the PaVLD was recovered and left for $6 \mathrm{~h}$ at room temperature to allow any remaining chloroform to evaporate. The same procedure was carried out with BG-11 media as a control. The chloroform-treated PaV-LD suspension, chloroform-treated media, non-treated PaV-LD suspension and non-treated BG-11 media were added to exponentially growing $P$. agardhii cultures. All cultures were incubated under the conditions described above.

\section{RESULTS AND DISCUSSION}

Planktothrix agardhii are planktonic filamentous cyanobacteria with abundant gas vacuoles, and grow by means of binary fission. The color of healthy $P$. agardhii cultures is blue-green. Trichomes are straight or slightly curved. The average length of each normal trichome is $215 \mu \mathrm{m}(\mathrm{SD}=58 \mu \mathrm{m}, \mathrm{n}=35)$ (Fig. 1A). Cell length is about $3.5 \mu \mathrm{m}(\mathrm{SD}=0.5 \mu \mathrm{m}, \mathrm{n}=35)$, cell width is about $3.3 \mu \mathrm{m}(\mathrm{SD}=0.3 \mu \mathrm{m}, \mathrm{n}=35)$ and the ratio of cell length to width is about 1.06:1.

In the first isolating process, within $8 \mathrm{~d}$, lysis of host cells was detected in Planktothrix agardhii HAB0637 cultures inoculated with the filtered freshwater. The cultures' color visibly changed from normal healthy green to pale yellow due to the degradation or release of cell contents of the host organisms. The average length of the lysed filaments of hosts became approximately $35 \mu \mathrm{m}(\mathrm{SD}=10 \mu \mathrm{m}, \mathrm{n}=35$ ) (Fig. 1B), which was much shorter than that of the normal filaments. Presumably, viruses simultaneously attacked some parts of a single filament in the early stages of viral infection and then the infected parts were lysed and gradually became discolored (Fig. 1C). Serial inoculation of the viral lysates into fresh exponentially growing $P$. agardhii HAB0637 cultures led to the same algicidal symptoms. The PaV-LD suspension filtered through a $0.2 \mu \mathrm{m}$ pore-size filter still retained algicidal activity; however, cell lysis of the cultures occurred later compared to the non-treated pathogen suspension (data not shown). It is probable that the lag of algicidal activity is due to adsorption of the partial infectious agents onto filters.

The host range of the PaV-LD was tested on 10 cyanobacterial species (24 strains). The PaV-LD infected and lysed 4 strains of Planktothrix agardhii (HAB0637, HAB0638, HAB0642, HAB0643) isolated from Lake Donghu, but failed to cause lysis of any other cyanobacterial species or strains tested, including 5 strains of $P$. agardhii isolated from 4 different lakes throughout China (shown in Table 1). These results demonstrated that the host range specificity of the PaV-LD was correlated with the geographical locations of host isolation. To explain what determines the infection specificity of the PaV-LD against $P$. agardhii, both ecological and physiological studies should be performed by collecting more strains of the host species from different regions.

Optical microscopic observation and chlorophyll fluorescence results show growth of Planktothrix agardhii HAB0637 cultures in the absence and presence of the PaV-LD suspension. In the infected cultures, most of the host filaments settled to the bottom of the incubation flask and lost mobility, and then lysis of host cells occurred within 2 to $3 \mathrm{~d}$ after the inoculation. 

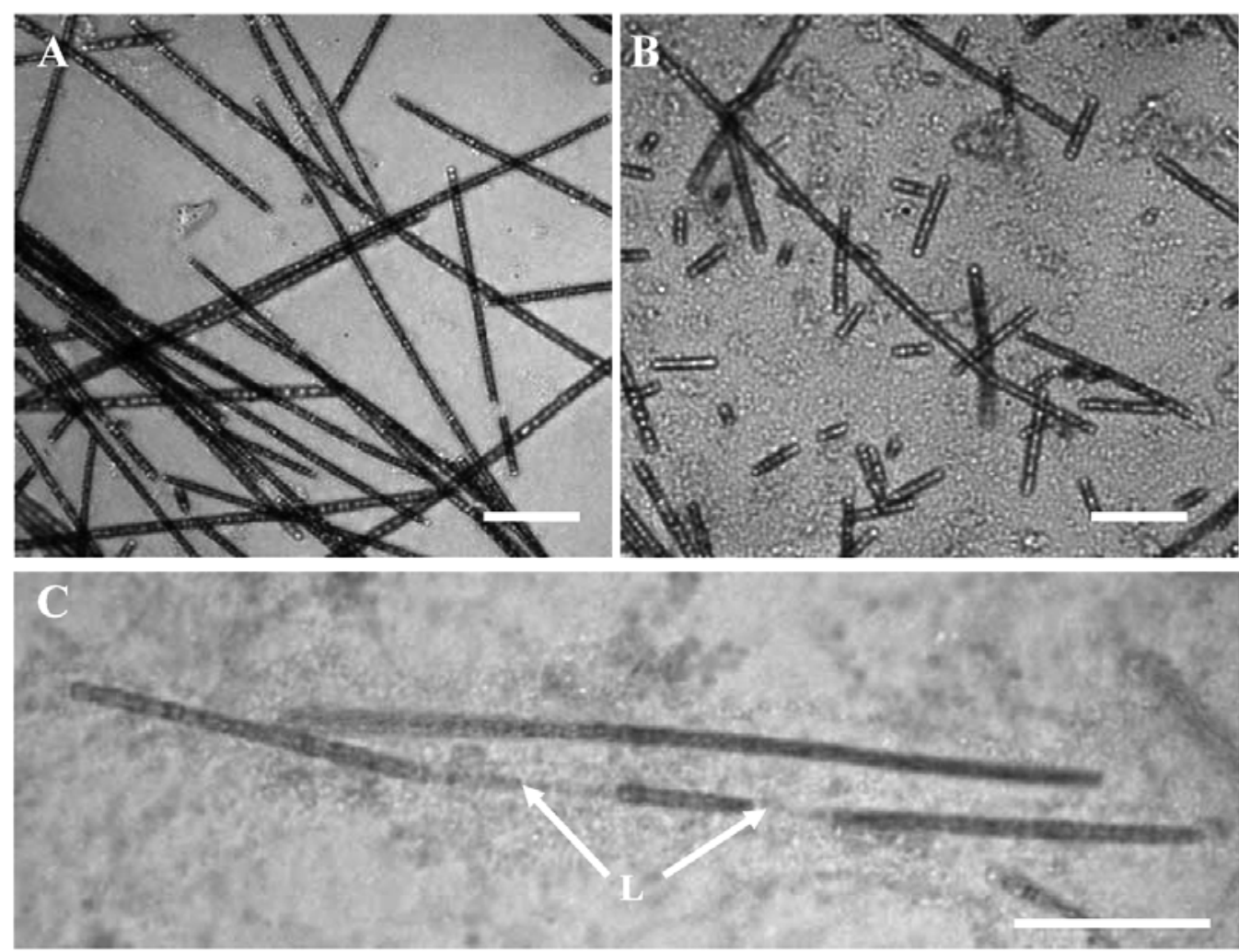

Fig. 1. Planktothrix agardhii. Optical microphotographs of (A) healthy cultures, (B) HAB0637 cultures $48 \mathrm{~h}$ after inoculation with cyanophage PaV-LD and (C) 2 parts of a single HAB0637 filament lysed (L). Scale bars $=50 \mu \mathrm{m}$

In contrast, the healthy cultures kept growing exponentially (Fig. 2). In the 1-step growth experiments, the growth parameters of PaV-LD were estimated. The cell density of $P$. agardhii HAB0637 began to decrease, and the titer of the PaV-LD to increase, $2 \mathrm{~d}$ after infection (Fig. 3), indicating that the PaV-LD phage has a latent period of 48 to $72 \mathrm{~h}$. At $6 \mathrm{~d}$ after inoculation, the density of host cells decreased to $2.70 \times 10^{3}$ from $8.20 \times$ $10^{5}$ cells ml ${ }^{-1}$, while the virus titer increased to $2.78 \times$

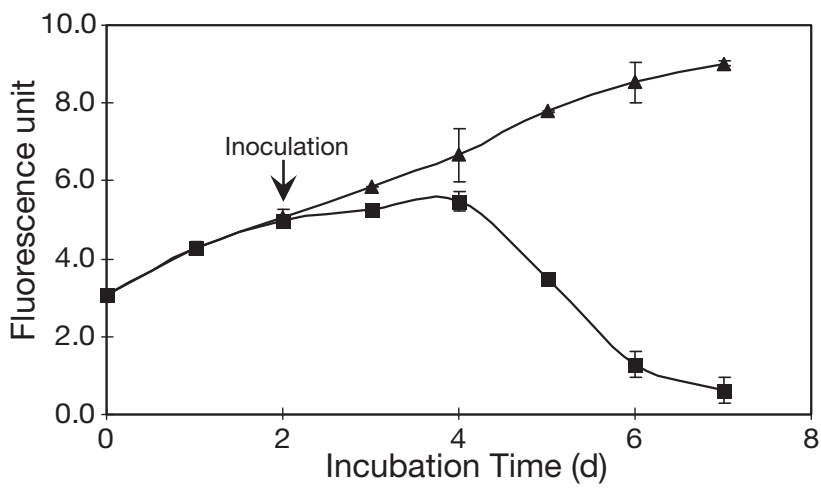

Fig. 2. Planktothrix agardhii. Algicidal curves of HAB0637 cultures as measured by chlorophyll fluorescence, showing

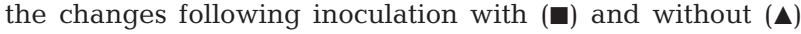
the PaV-LD suspension. Values are means $\pm \mathrm{SD}(\mathrm{n}=3)$
$10^{8}$ from $3.70 \times 10^{5}$ infectious units $\mathrm{ml}^{-1}$. From the decline in host cell abundance and the concurrent increase in phage abundance, about 340 infectious particles were estimated to be released by each $P$. agardhii cell infected with the PaV-LD phage. Compared with the other cyanophages whose growth characteristics have been studied (Tucker \& Pollard 2005, Yoshida et al. 2006), the latent period and average

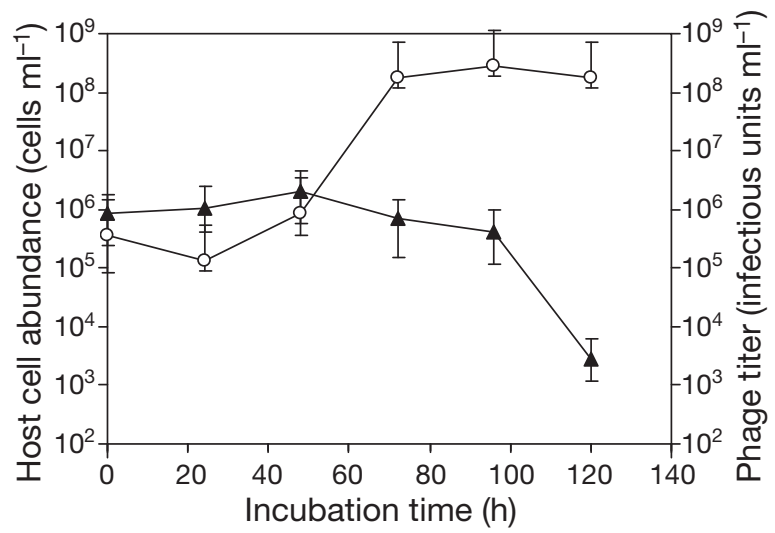

Fig. 3. Growth curves of cyanophage PaV-LD. Changes in abundance of cyanophage PaV-LD (O) and the density of Planktothrix agardhii host cells $(\mathbf{\Lambda})$ in a 1-step growth experiment. The initial multiplicity of infection was about 0.45 . The error bars indicate $95 \%$ confidence limits $(0)$ or SD values ( $(\mathbf{\Lambda})$ 
burst size of the PaV-LD are much longer and greater, respectively. This could be the result of the large size of the host cells. Here, our estimates were only approximations, and the latent period and burst size of this cyanophage may be associated with the growth and physiological status of host cells. Considering the initial mode of infection and host cell lysis, most $P$. agardhii cells did not escape the PaV-LD infection. However, a small number of filaments and short fragments were observed in the culture lysates, indicating that the lysis of the PaV-LD was not complete. These surviving host filaments recovered to an exponentially growing phase within several weeks when they were cultured in fresh BG-11 medium. The re-growth cultures were not lysed by an addition of the PaV-LD suspension. This could be explained by the resistance acquired by the host to the cyanophage (Waterbury \& Valois 1993).

Transmission electron microscopy of ultra-thin sections of Planktothrix agardhii HAB0637 filaments infected with the PaV-LD suspension revealed that there had been propagation of viral particles inside the thylakoid space and the nucleiod (Fig. 4B). None of the virus-like particles were observed in the healthy filaments (Fig. 4A). Furthermore, numerous virus particles with similar size and morphology were observed in the culture lysates (Fig. 5). The viral particles were uniformly hexagonal or circular in cross section, indicating that the virus had an icosahedral symmetry and was tail-less, unlike most isolated cyanophages that have a contractile tail. The average diameter of viral particles ranged from 70 to $85 \mathrm{~nm}$ (mean $\pm \mathrm{SD}=76 \pm$ $6 \mathrm{~nm}$ ). Due to the atypical morphology of the nontailed structure, these cyanophages may have some uncommon features (Bergh et al. 1989, McDaniel et al. 2006), such as nucleic acid gene content. For example, the non-tailed virus particle does not contain a readily identifiable $g 20$ gene encoding the viral capsid structure, which is a conservative phylogenetic marker for the cyanomyoviruses (Fuller et al. 1999, Zhong et al. 2002, McDaniel et al. 2006). Therefore, further studies are needed to characterize the PaV-LD phage at the gene or genomic level.

The significant results of our study indicated that (1) the algicidal factors could be transferred to a fresh host culture, (2) virus-like particles were observed in the lysed culture and (3) virus-like particles were not detected in healthy culture, which are common characteristics of other isolated cyanobacterial viruses. Therefore, the virus-like particles observed within infected cells and in the culture lysates were both morphologically and physiologically considered to be a cyanophage. This cyanophage was tentatively named PaV-LD (Planktothrix agardhii Virus isolated from Lake Donghu) after its host and the location from which it was isolated.

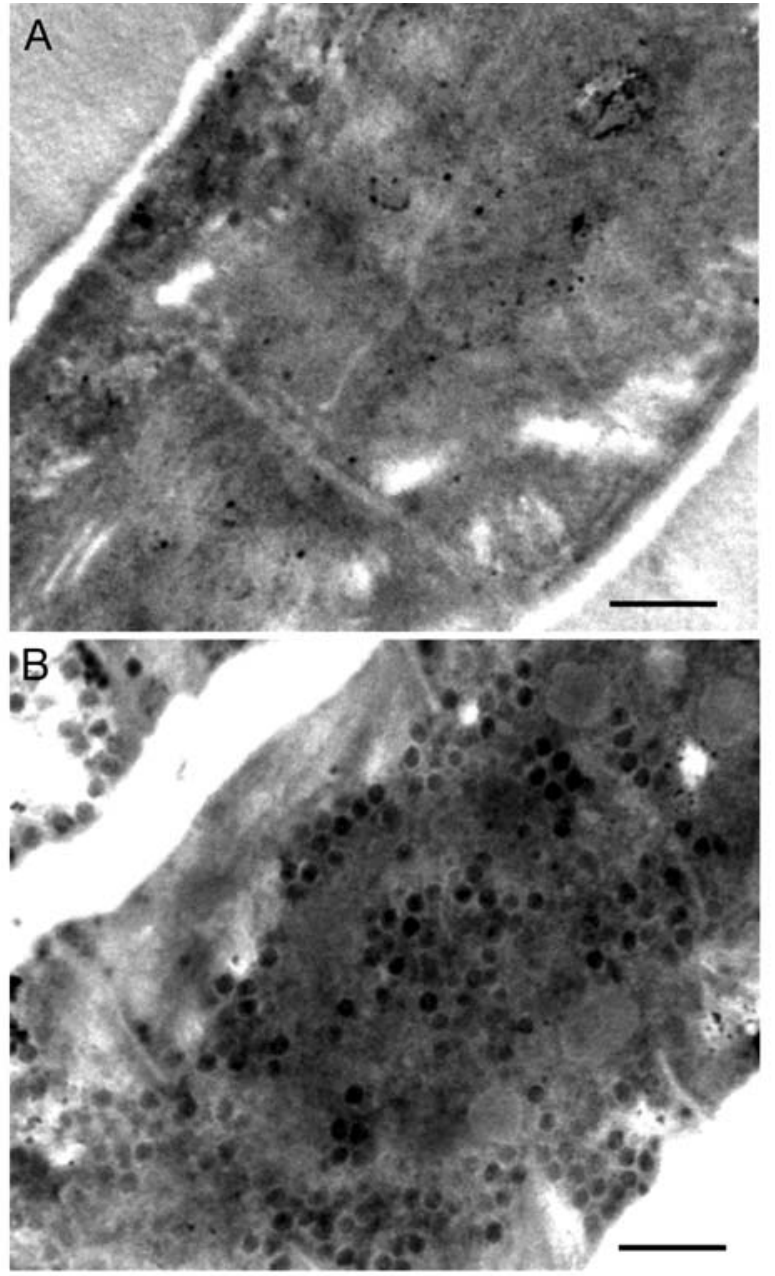

Fig. 4. Planktothrix agardhii. Transmission electron micrographs of ultra-thin sections of (A) a healthy filament of HAB0637 and (B) a HAB0637 filament $48 \mathrm{~h}$ after infection with PaV-LD. Scale bars $=500 \mathrm{~nm}$

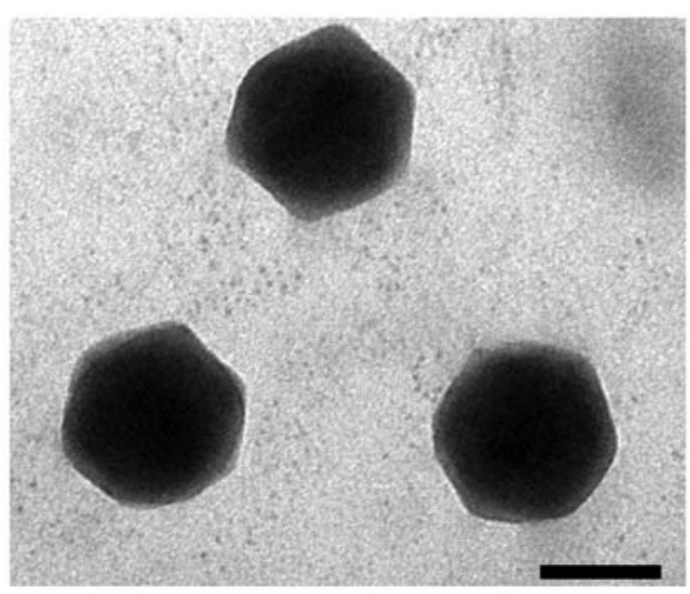

Fig. 5. Transmission electron micrograph of cyanophage PaV-LD particles. Scale bar $=50 \mathrm{~nm}$ 
The PaV-LD was stable to freezing for $1 \mathrm{wk}$ at -20 , -80 and $-196^{\circ} \mathrm{C}$ (liquid nitrogen) in the dark without cryoprotectants, suggesting that the virus can be stored for even longer times for future use. When subjected to temperatures over $50^{\circ} \mathrm{C}$, the PaV-LD lost its ability to cause lysis of host cells, indicating that the $\mathrm{PaV}$-LD is heat-labile. The virus was inactivated after exposure to acidic $\mathrm{pH}(\leq 4)$, and resistant to treatment with chloroform, which resulted in about a $3 \mathrm{~d}$ delay in lysis of host cells in the present experiment, suggesting lack of a lipid component in the structure of the virus (Fenner et al. 1974).

The filamentous cyanobacterial genus Planktothrix is one of the most important planktonic cyanbacteria that form intense blooms that occur periodically or persist all year round (Scheffer et al. 1997, Briand et al. 2002). They are global in distribution and contain a large number of species, including toxin-producing and nontoxin-producing species (Sivonen \& Jones 1999). The successful isolation of the PaV-LD shows that viruses that infect and lyse the filamentous cyanobacterium $P$. agardhii are an active component of natural aquatic environments. Considering that the PaV-LD strain was isolated from natural freshwater where its host cyanobacterium P. agardhii HAB0637 was isolated, it is probable that there is a close interaction between PaV-LD and $P$. agardhii in the natural environment. Based on results from the present study, cyanophage PaV-LD may be used as a good microbiological agent for causing host mortality because it can be proliferated in the lab at a relatively low cost, specifically attack the target cyanobacterium $P$. agardhii and has no harmful effects on other organisms. If the growth characteristics of PaV-LD estimated in the 1-step growth experiment were used, the potential infectivity could contribute in controlling $P$. agardhii blooms. However, resistance of the host to the phage may be one of the limiting factors of using this infectious agent for cyanobacterial blooms in natural environments. Further studies will be performed to determine the mechanism of viral resistance and lysogeny. Although the host-virus system was recently isolated from natural water, the detailed information about the ecological effects of the PaV-LD is still unknown. More studies need be carried out to address the biological features of the $\mathrm{PaV}-\mathrm{LD}$, and its algicidal activity under different environmental conditions, such as light and nutrient levels.

Acknowledgements. We thank Professor Li-Rong Song and Mr. Sen Lin for help in algae collection and culture. This work was supported by grants from the National Major Basic Research Program (grant no. 2004CB117403), the National 863 High Technology Research Foundation of China and the National Natural Science Foundation of China (grant nos. 30671616 and U0631008).

\section{LITERATURE CITED}

Bergh O, Borsheim KY, Bratbak G, Heldal M (1989) High abundance of viruses found in environments. Nature 340:467-468

Briand JF, Robillot C, Quiblier-Llobe'ras C, Bernard C (2002) A perennial bloom of Planktothrix agardhii (cyanobacteria) in a shallow eutrophic French lake: limnological and microcystin production studies. Arch Hydrobiol 153: $605-622$

Chorus I, Bartram J (1999) Toxic cyanobacteria in water: a guide to their public health consequences, monitoring and management. E \& FN Spon, London

> Davis PA, Dent M, Parker J, Reynold CS, Walsby AE (2003) The annual cycle of growth rate and biomass change in Planktothrix spp. in Blelham Tarn, English Lake. Freshw Biol 48:852-867

Fenner F, McAuslan BR, Mims CA, Sambrook J, White DO (1974) The biology of animal viruses. Academic Press, New York

Fuller N, Wilson WH, Mann NH (1999) Occurrence of T4 g20 homologues in marine cyanophages and their application to PCR-based detection and quantification techniques. Appl Environ Microbiol 64:2051-2060

> Hewson I, O'Neil JM, Dennison WC (2001) Virus-like particles associated with Lyngbya majuscula (Cyanophyta; Oscillatoriacea) bloom decline in Moreton Bay, Australia. Aquat Microb Ecol 25:207-213

Li R, Wilhelm SW, Carmichael WW, Watanabe MM (2008) The morphological, physiological, biochemical and molecular characterization of two strains of Raphidiopsis (Cyanobacteria) from a fishpond in central China. Harmful Algae 7:146-153

Liu YM, Zhang QY, Yuan XP (2005) Abundance and diversity of virioplankton in Lake Donghu, Wuhan. Acta Hydrobiology Sinica 29:1-6 (in Chinese with English abstract)

Liu YM, Yuan XP, Zhang QY (2006) Spatial distribution and morphological diversity of virioplankton in Lake Donghu, China. Acta Oecol 29:328-334

> Lu J, Chen F, Hodson RE (2001) Distribution, isolation, host specificity and diversity of cyanophages infecting marine Synechococcus spp. in river estuaries. Appl Environ Microbiol 67:3285-3290

McDaniel LD, delaRosa M, Paul JH (2006) Temperate and lytic cyanophages from the Gulf of Mexico. J Mar Biol Assoc UK 86:517-527

Nagasaki K, Yamaguchi M (1997) Isolation of a virus infectious to the harmful bloom causing microalga Heterosigma akashiwo (Raphidophyceae). Aquat Microb Ecol 13:135-140

Padan E, Shilo M (1973) Cyanophage-viruses attacking bluegreen algae. Bacteriol Rev 37:343-370

Phlips EJ, Monegue RL, Aldridge FJ (1990) Cyanophages which impact bloom-forming cyanobacteria. J Aquat Plant Manag 28:92-97

> Proctor LM, Fuhram JA (1990) Viral mortality of marine bacteria and cyanobacteria. Nature 343:60-62

Safferman RS, Morris ME (1963) Algal virus isolation. Science 140:679-680

Saitoh S, Iwasaki K, Yagi O (2003) Development of a mostprobable-number method for enumerating denitrifying bacteria by using 96 -well microtiter plates and an anaerobial culture system. Microbes Environ 18:210-215

Scheffer M, Rinaldi S, Gragnani A, Mur LR, Van Nes EH (1997) On the dominance of filamentous cyanobacteria in shallow turbid lakes. Ecology 78:272-282

Sivonen K, Jones GJ (1999) Cyanobacterial toxins. In: Chorus 
I, Bartram J (eds) Toxic cyanobacteria in water. E \& FN Spon, London, p 41-111

Suda S, Watanabe MM, Otsuka S, Mahakahant A and others (2002) Taxonomic revision of water-bloom-forming species of oscillatorioid cyanobacteria. Int J Syst Evol Microbiol 52:1577-1595

Suttle CA (2000) Cyanophages and their role in the ecology of cyanobacteria. In: Whitton BA, Potts M (eds) The ecology of the cyanobacteria. Kluwer Academic Publishers, Dordrecht, p 563-589

Suttle CA (2005) Viruses in the sea. Nature 437:356-361

Suttle CA, Chan AM (1994) Dynamics and distribution of cyanophages and their effect on marine Synechococcus spp. Appl Environ Microbiol 60:3167-3174

Suttle CA, Chan AM, Cottrell MT (1990) Infection of phytoplankton by viruses and reduction of primary productivity. Nature 347:467-469

Tonk L, Visser PM, Christiansen G, Dittmann E and others (2005) The microcystin composition of the cyanobacterium Planktothrix agardhii changes toward a more toxic variant with increasing light intensity. Appl Environ Microbiol 71: $5177-5181$

Tucker S, Pollard P (2005) Identification of cyanophage Ma-LBP and infection of the cyanobacterium Microcystis aeruginosa from an Australian subtropical lake by the virus. Appl Environ Microbiol 71:629-635

Wang K, Chen F (2008) Prevalence of highly host-specific

Editorial responsibility: Curtis Suttle,

Vancouver, British Columbia, Canada cyanophages in the estuarine environment. Environ Microbiol 10:300-312

Waterbury JB, Valois FW (1993) Resistance to co-occurring phages enables marine Synechococcus communities to coexist with cyanophage abundant in seawater. Appl Environ Microbiol 59:3393-3399

Weinbauer MG (2004) Ecology of prokaryotic viruses. FEMS Microbiol Rev 28:127-181

> Wiegand C, Pflugmacher S (2005) Ecotoxicological effects of selected cyanobacterial secondary metabolites: a short review. Toxicol Appl Pharmacol 203:201-218

Wommack KE, Colwell RR (2000) Virioplankton: viruses in aquatic ecosystems. Microbiol Mol Biol Rev 64:69-114

> Yoshida M, Yoshida T, Kashima A, Takashima Y, Hosoda N, Nagasaki K, Hiroishi S (2008) Ecological dynamics of the toxic bloom-forming Microcystis aeruginosa and its cyanophages in freshwater. Appl Environ Microbiol 74: 3269-3273

Yoshida T, Takashima Y, Tomaru Y, Shirai Y, Takao Y, Hiroishi S, Nagasaki K (2006) Isolation and characterization of a cyanophage infecting the toxic cyanobacterium Microcystis aeruginosa. Appl Environ Microbiol 72:1239-1247

Zhong Y, Chen F, Wilhelm SW, Poorvin L, Hodson RE (2002) Phylogenetic diversity of marine cyanophage isolates and natural virus communities as revealed by sequences of viral capsid assembly protein gene g20. Appl Environ Microbiol 68:1576-1584

Submitted: November 15, 2007; Accepted: November 6, 2008 Proofs received from author(s): February 3, 2009 